\title{
Conversion of Carbon Dioxide to Methanol Using Solar Energy—A Brief Review
}

\section{Ibram Ganesh}

Centre for Photoelectrochemical (PEC) Cells and Advanced Ceramics, International Advanced Research Centre for Powder Metallurgy and New Materials (ARCI), Hyderabad, India.

Email: ibram_ganesh@yahoo.com

Received February $3^{\text {rd }}, 2011$; revised March 23 ${ }^{\text {rd }}, 2011$; accepted April $2^{\text {nd }}, 2011$.

\begin{abstract}
This article presents a meticulous and comprehensive review of literature reported on conversion of carbon dioxide, a green house gas into methanol or to any other value added chemical following various routes including catalytic, thermal, biological, electrochemical and photoelectrochemical (PEC). More emphasis is given on conversion of carbon dioxide to methanol using solar energy (i.e., artificial photosynthesis) as this process can tackle the human generated two pressing problems, i.e., "global warming" and "energy crisis" today world is facing. It also covers information on various materials required for designing and development of reliable PEC cells for conversion of carbon dioxide to more value added chemicals including methanol. Finally, it also provides the scope for the future research on this topic with adequate literature support.
\end{abstract}

Keywords: Solar Energy, Carbon Dioxide, Methanol, Photoelectrochemical Cells

\section{Introduction}

Recently, the selective catalytic reduction of carbon dioxide $\left(\mathrm{CO}_{2}\right)$ to value added chemicals using solar energy has received a great deal of attention from the scientific community as it can in deed solve two major problems, i.e., "Global Warming" [1-4] and "Energy Crisis" [5-9] today world is facing. Atmospheric $\mathrm{CO}_{2}$ resulting from burning of fossil fuels to meet energy needs of human beings is mainly responsible for global warming that is posing severe problems to both ecology and human beings. Recently, the Intergovernmental Panel on Climate Change (IPCC) has also concluded that the increasing $\mathrm{CO}_{2}$ concentrations resulting from fossil fuel burning and deforestation are responsible for most of the observed global warming [2]. Most national governments have signed and ratified the Kyoto Protocol [3] of the United Nations Framework Convention on Climate Change aimed at reducing greenhouse gas emissions [4]. On the other hand, today $90 \%$ of the world's primary energy requirement is met by fossil fuels and for at least next few decades these fossil fuels are going to be the only energy resources as alternative reliable renewable energy resources are yet to be fully realized. The world reserve of natural gas is estimated as about $10^{14} \mathrm{~m}^{3}$; this has a significant impact on the world's energy balance. As per an estimation, at the current rate of use, these reserves will last for 60 years, compared with 30 years for crude oil reserves [1-4]. On the other hand, self sufficiency in energy is a stated national goal for all the countries. Most of the proposed means to achieve this goal are either environmentally unacceptable or are not feasible, especially those not depending on fossil fuel resources [10-20]. Of the available alternatives, solar energy is the most abundant, inexhaustible single resource available. Solar energy as available on the surface of the earth constitutes clean, non-polluting, abundant and relatively "free" resource. As much solar energy falls on earth's surface in a fortnight as the energy contained in the world's fossil fuel resources $\left(10^{16} \mathrm{~kW}\right)$. The mean solar irradiance at normal incidence outside the atmosphere is $1360 \mathrm{~W} / \mathrm{m}^{2}$ and the total annual incidence of solar energy in India alone is about $10^{7} \mathrm{~kW}$ and for the southern region the daily average is about $0.4 \mathrm{~kW} / \mathrm{m}^{2}$ [11]. However, capturing and utilizing solar energy is not simple. Methods are being sought to convert solar energy into a concentrated, storable form of energy. Nature via photosynthesis converts somewhat less than $1 \%$ of the sun's energy at the earth's surface to a solid fuel, i.e., plant materials, which when accumulated and transformed over geologic ages 
yielded fossil fuels. Current rates of use of these fossil fuels, and the particular geographic distribution and political control of major petroleum resources pose problems for nations that are net petroleum consumers [5-9]. Hence, an alternative method yielding a simple fuel, at a higher conversion, has long been desired. The conversion of $\mathrm{CO}_{2}$ into more useful organic fuels (like methanol) using energy that is not produced from fossil fuels is believed to be one such alternative method. It is also strongly believed that the artificial photosynthesis has tremendous potential, even though it remains to be successfully demonstrated on a commercial basis. It is a scientific challenge, and if this process is successful, the market will be gigantic. Considering the importance of solar assisted conversion of carbon dioxide to methanol from the point of view of global warming and energy crisis, the complete literature available on this topic has been reviewed and presented in this article along with the merits and demerits associated with each reported process.

\section{Methods Available for Conversion of Carbon Dioxide to Value Added Chemicals}

Methanol is the most promising photo-reduced product of carbon dioxide because it can be transformed into other useful chemicals such as gasoline (petrol) using conventional chemical technologies, or easily transported and used as fuel in the automobile vehicles without major adjustments [21-28]. There are several other motivations as listed below for producing methanol or any other useful chemical from carbon dioxide [29-35]. 1) Carbon dioxide is an inexpensive, nontoxic feedstock that can frequently replace toxic chemicals such as phosgene of isocyanates. 2) Carbon dioxide is a renewable feedstock compared to oil or coal. 3) The production of chemicals from carbon dioxide can lead to new industrial productivity. 4) New routes to existing chemical intermediates and products could be more efficient and economical than current methods. 5) The production of chemicals from carbon dioxide could have a small but significant impact on the global carbon balance. Considering these benefits, several technologies have been proposed for utilization of carbon dioxide and for improving the efficiency of energy conversion. The most successful reaction of these types is the Sabatier process [36]. This process involves the reaction of hydrogen with carbon dioxide at elevated temperatures and pressures in the presence of a nickel catalyst to produce methane and water $\left(\mathrm{CO}_{2}+4 \mathrm{H}_{2} \rightarrow \mathrm{CH}_{4}+2 \mathrm{H}_{2} \mathrm{O}\right)$. It was discovered by the French chemist Paul Sabatier. It has been proposed as a key step in reducing the cost of manned exploration of Mars (Mars Direct) through in-situ resource utilization. After producing water by combining hydrogen trans- ported from Earth and carbon dioxide taken from the atmosphere of Mars, oxygen would be extracted from the water by electrolysis and used as a rocket propellant. The stoichiometric propulsion fuel mix ratio is $1: 8$ between hydrogen and oxygen by weight (each pound of hydrogen requires 8 pound of oxygen to burn), and if only the light hydrogen has to be transported, and the heavy oxygen extracted locally, that would result in a very considerable weight savings which would have to be transported to Mars. Nevertheless, the expensive electrolysis technique employed in the Sabatier process for splitting water into oxygen and hydrogen is not economical to practice for vehicles those run on the road.

On the other hand, electrochemical systems developed for reducing $\mathrm{CO}_{2}$ to methanol or methane involve high electrode over-potentials, which offer little or no advantage since the quantity of fuel consumed during the synthesis of the reduction products far exceeds the fuel value of the products [34-36]. Whereas, the catalytic hydrogenation of $\mathrm{CO}_{2}$ to methanol has also been found to be not encouraging due to the involvement of high reaction temperatures [34]. Even, the electrocatalytic reduction of carbon dioxide to formic acid or carbon monoxide at Pd, $\mathrm{Pt}$ and $\mathrm{Hg}$ electrodes were also found to be not commercially viable [37-39]. The production cost of processes involving reduction of $\mathrm{CO}_{2}$ to methanol such as, high temperature catalytic-vapour phase reaction of $\mathrm{CO}_{2}$ with water vapour, thermo-chemical/electro-chemical reduction of $\mathrm{CO}_{2}$, etc., has been found to be not economical [10].

The main reason for un-economical production of methanol or any other useful chemical from $\mathrm{CO}_{2}$ is the endothermic nature of these reactions (for example, $\mathrm{CO}_{2(\mathrm{~g})}$ $+2 \mathrm{H}_{2} \mathrm{O}_{(\mathrm{l})} \rightarrow \mathrm{CH}_{3} \mathrm{OH}_{(\mathrm{l})}+3 / 2 \mathrm{O}_{2(\mathrm{~g})} ; \mathrm{H}^{\mathrm{o}}-727 \mathrm{~kJ} \cdot \mathrm{mol}^{-1}$ and $\left.\mathrm{G}^{\mathrm{o}}-703 \mathrm{~kJ} \cdot \mathrm{mol}^{-1}\right)$.

Given the $\mathrm{CO}_{2}$ reduction process is thermodynamically uphill $\left(\mathrm{CO}_{2}+6 \mathrm{H}^{+}+6 \mathrm{e}^{-} \rightarrow \mathrm{CH}_{3} \mathrm{OH}+\mathrm{H}_{2} \mathrm{O} ; \mathrm{E}^{\circ}=\right.$ $-0.38 \mathrm{~V}$ ), economical reduction of $\mathrm{CO}_{2}$ to value added chemicals is possible only if renewable energy, such as solar energy, is used as the energy source. In fact, plant photosynthesis has long been studied with an eye to understanding its underlying mechanisms and then applying this knowledge to the production of energy for the needs of society [40]. Solar energy can be harnessed to drive $\mathrm{CO}_{2}$ conversion by: 1) artificial photosynthesis using homogeneous and heterogeneous systems; 2) electrochemical reduction using solar electric power; and 3) hydrogenation of $\mathrm{CO}_{2}$ using solar-produced hydrogen, i.e., using photoelectrochemical (PEC) cells. Though, these routes exhibited ability to convert $\mathrm{CO}_{2}$ to $\mathrm{CH}_{3} \mathrm{OH}$, $\mathrm{HCOOH}, \mathrm{HCHO}, \mathrm{CH}_{3} \mathrm{OCH}_{3}$, $\mathrm{CO}$, etc., they suffered from several limitations such as, poor performance, un-stability of associated catalysts and semi-conductors in water, in-efficiency of electrolytic systems, inferior reduc- 
ing cathode materials, etc. Nevertheless, photoelectrochemical (PEC) conversion of $\mathrm{CO}_{2}$ to methanol appears to be more promising among various other routes [41].

\section{Photoelectrochemical (PEC) Cells}

In a study, Halmon [10] demonstrated that aqueous carbon dioxide could be reduced on semiconductor surfaces such as p-type gallium phosphide to produce formic acid, formaldehyde and methanol in a photo-assisted electrolytic reaction using photoelectrochemical (PEC) cells. In fact, PEC conversion of visible light to chemical or electrical energy has the potential of being a relatively efficient process. PEC cells enable solar energy utilization to meet many of the energy needs of the future [42-58]. These cells involve the application of liquid-junction transducers to solar energy conversion. Semiconductorelectrolyte junction devices of these cells have an advantage over solid state photo-voltaics in that 1) they can directly generate hydrogen or carry out other photo-redox processes, and 2) they can use polycrystalline semiconductor electrodes. The junction is easily prepared merely by dipping the electrode in the electrolyte, in contrast to solid state junctions which have to be prepared by diffusion or ion implantation. However, the efficiency of so far studied PEC cells was found to be low and the semiconductor photoelectrodes employed exhibited poor stability against water reaction under solar irradiation.

Photoelectrolysis of water or reduction of $\mathrm{CO}_{2}$ require thermodynamic energy inputs of 1.23 and $1.5 \mathrm{eV}$, respectively. Greater energy input is required to make up for losses due to band bending (necessary in order to separate charge at the semiconductor surface), resistance losses, and overvoltage potentials [42-58]. Furthermore, when a semiconductor is placed in an electrolyte, partial differences between the two phases result in charging of the interface, as in a capacitor. This charging results in a perturbation of the energy levels of the semiconductor called "band-bending". Band-bending is responsible for separation of electron-hole pairs in photoelectrochemical processes. Recombination and corrosion processes decrease the utilization of the electron-hole pairs generated on illumination. Photoelectrolysis of water at high efficiency is also hampered by a number of problems. First, the overvoltages of the hydrogen and oxygen couples at most moderate band gap $(1.0<\mathrm{Eg}<2.0 \mathrm{eV})$ semiconductors are substantial. Second, if electron or hole transfer to the substrate does not occur rapidly, recombination of electron-hole pairs can occur at surface defects or grain boundaries in polycrystalline samples [42-58].

These two problems arise, at least in part, from one fundamental deficiency. While the electrolyte-semiconductor interface has excellent characteristics for separation of charge and generation of high oxidation or reduc- tion potentials when irradiated, it often has very poor catalytic properties for reactions with significant activation energies. Water is particularly an attractive source of hydrogen for the reduction of $\mathrm{CO}_{2}$ as well as for the direct generation of $\mathrm{H}_{2}$. Water can only be used, however, if the semiconductor electrodes are stable in its presence. It has been demonstrated that, the production of energy-rich materials (e.g., $\mathrm{H}_{2}, \mathrm{CH}_{3} \mathrm{OH}, \mathrm{CH}_{2} \mathrm{O}, \mathrm{CH}_{2} \mathrm{O}_{2}$, and $\mathrm{NH}_{3}$ ) is associated with $\mathrm{O}_{2}$ evolution [42-58]. A major problem in photoelectrochemistry is that the oxidation of water at the photoanode of non-oxide n-type materials is thermodynamically and kinetically disfavoured over the reaction of the valence band holes with the semiconductor lattice. In fact, all known non-oxide and many oxide n-type photoanodes are susceptible to photodegradation in aqueous electrolytes.

In spite of its great economic and social importance, only a few papers have dealt with selective reduction of carbon dioxide to value added chemicals using renewable solar energy as the reaction promoting aid. The first important step of the photoelectrochemical (PEC) reduction of $\mathrm{CO}_{2}$ to methanol is the generation of hydrogen ions and electrons by the solar irradiance of semi-conducting photoanode. Upon illumination of the semiconductor with light energy equal to or greater than that of the semiconductor bandgap, electrons are promoted from the valence band to the conduction band, creating electronhole pairs at or near the interface. The electron-hole pairs are spatially separated by the semiconductor junction barrier, and are injected into the electrolyte at the respective electrodes to produce electrochemical oxidation and reduction reactions [59-61]. A major impediment to the exploitation of photoelectrochemical cells in solar energy conversion and storage is the susceptibility of small bandgap semiconductor materials to photoanodic and photocathodic degradation. The photoinstability is particularly severe for n-type semiconductors where the photogenerated holes, which reach the interface, can oxidize the semiconductor itself. In fact, all known semiconducting materials are predicted to exhibit thermodynamic instability toward anodic photodegradation. Whether or not an electrode is photostable then depends on the competitive rates of the thermodynamically possible reactions, namely, the semiconductor decomposition reaction and the electrolyte reactions.

\section{Transition-Metal Complexes as Photo-Sensitizers and Catalysts}

In a study, Williams and Rembaum have modified the electrodes surfaces with electron mediators such as, N,N'dimethyl, 4,4'-bipyridinium (methyl viologen, $\mathrm{MV}^{+2}$ ) to enhance rates of photoelectrochemical reactions and suppress photo-corrosion and recombination [52]. $\mathrm{MV}^{+2}$ has 
been shown to be an efficient electron transfer catalyst for $\mathrm{H}_{2}$ evolution. The role of the $\mathrm{MV}^{+2} / \mathrm{MV}^{+1}$ system is to provide an oxidized material which is efficiently photoreduced and a reduction product which can efficiently transfer electrons to water or hydrogen ions at metal (platinum) catalysts to produce $\mathrm{H}_{2}$,

$$
\mathrm{MV}^{+2} \stackrel{\mathrm{hv}, \mathrm{E}}{\longrightarrow} \mathrm{MV}^{+1}
$$

On the surface of p-type semiconductor the following reaction occurs:

$$
\mathrm{MV}^{+1}+\mathrm{H}_{2} \mathrm{O} \stackrel{\mathrm{Pt}}{\longrightarrow} \mathrm{MV}^{+2}+\mathrm{OH}^{-}+1 / 2 \mathrm{H}_{2(\mathrm{~g})}
$$

The problems with mediation via solutions of methyl viologen are the intense absorption of visible light by the $\mathrm{MV}^{+1}$ species, and the relatively low concentration of the mediator.

Transition-metal complexes have also often been used as photochemical and thermal catalysts because they can absorb a significant portion of the solar spectrum, have long-lived excited states, can promote multielectron transfer and activate small molecules through binding [53]. In transition-metal complexes, a central metal has octahedral, tetrahedral, square planar, square-pyramidal, or trigonal-pyramidal symmetry depending on the surrounding ligands. Reduced metal centers such as $\mathrm{M}^{\mathrm{I}} \mathrm{L}$, in which the oxidation number of the central metal $(\mathrm{M})$ is plus one and the ligand (L) has four-coordinating atoms, typically have one or more vacant coordinate sites. These sites can be used to bind and activate $\mathrm{CO}_{2}$ (or other small molecules). The oxidative addition of $\mathrm{CO}_{2}$ to $\mathrm{M}^{\mathrm{I}} \mathrm{L}$ to form a metallocarboxylate, $\mathrm{M}^{\mathrm{III}} \mathrm{L}\left(\mathrm{CO}_{2}^{2-}\right)$, stabilizes the $\mathrm{CO}_{2}$ moiety through two-electron transfer. The $\mathrm{M}^{\mathrm{III}} \mathrm{L}$ $\left(\mathrm{CO}_{2}^{2-}\right)$ can then react with $\mathrm{H}^{+}$to form $\mathrm{M}^{\mathrm{III}} \mathrm{L}, \mathrm{CO}$ and $\mathrm{OH}^{-}$. The systems that have been used for photochemical $\mathrm{CO}_{2}$ reduction studies have been divided into the following steps:

1) $\mathrm{Ru}$ (bpy) $)_{3}^{2+}$ (bpy-2,2"-bipyridine) as both the photosensitizer and the catalyst;

2) $\mathrm{Ru}(\mathrm{bpy})_{3}^{2+}$ as the photosensitizer and another metal complex as the catalyst;

3) $\operatorname{ReX}(\mathrm{CO})_{3}(\mathrm{bpy}) \quad(\mathrm{X}=$ halide or phosphine-type ligand) or a similar complex as both the photosensitizer and the catalyst;

4) $\mathrm{Ru}(\mathrm{bpy})_{3}^{2+}$ or $\mathrm{Ru}(\mathrm{bpy})_{3}^{2+}$-type complex as the photosensitizer in microheterogeneous systems;

5) A metallophorphirin as both the photosensitizer and the catalyst;

6) Organic photosensitizers with transition-metal complexes as catalysts.

Mechanisms believed to be involved in the above process are: 1) light absorption by a photosensitizer to produce the excited state; 2) a quenching reaction between the excited state and an electron donor to produce a reduced complex; 3) electron transfer from the reduced complex to a catalyst; and 4) activation of $\mathrm{CO}_{2}$ by the reduced catalyst. However, the major products formed in this process are formic acid $(\mathrm{HCOOH})$ and carbon monoxide.

\section{Passivation of Semi-Conductor Surfaces against Photocorrosion}

A great variety of approaches have been made to control the photo-instability of the semiconductor-electrolyte interfaces using surface coating techniques. For example, to stabilize semiconductor surfaces from photodecomposition, non-corroding layers of metals or relatively stable semi-conductor films have been reported. These continuous metal films which block solvent penetration can protect n-type GaP electrodes from photo-corrosion. However, if the films are too thick for the photo-generated holes to penetrate without being scattered, they assume the Fermi energy of the metal. Then the system is equivalent to a metal electrolysis electrode in series with a metal-semi-conductor Schottky barrier. In such a system, the metal-semiconductor junction controls the photovolatge and not the electrolytic reactions. In general, a bias is required to drive the water oxidation. In other cases, the metal can form an Ohmic contact that leads to the loss of the photoactivity of the semiconductor. In discontinuous metal coatings, the electrolyte contacts the semiconductor, a situation which can lead to photo-corrosion. For example, discontinuous gold films do not seem to protect n-type GaP from photo-corrosion [4258].

Corrosion-resistant wide-bandgap oxide semiconductor $\left(\mathrm{TiO}_{2}\right.$ and titanates mostly) coatings over narrow-bandgap n-type semiconductors such as $\mathrm{GaAs}, \mathrm{Si}, \mathrm{CdS}, \mathrm{GaP}$, and InP have been shown to impart protection from photodecomposition. One of two problems is currently associated with the use of optically transparent, wide-bandgap semiconducting oxide coatings: either a thick film blocks charge transmission, or a thin film still allows photocorrosion $[47,48]$.

\section{The Electro-Active and the Charge Conductive Polymers}

In a study it has been shown that chemical bonding of electroactive polymers to the semiconductor surface affects the interfacial charge-transfer kinetics such that the less thermodynamically favoured redox reaction in the electrolyte predominates over the thermodynamically favoured semiconductor decomposition reaction [48]. To date, emphasis has been placed on improving the catalytic properties of p-type electrodes, where photocorrosion by reductive processes is not a major problem. The overvoltage for the evolution of hydrogen from p-type 
electrode surfaces is normally quite large. It has been demonstrated, however, that the catalytic property of a p-type Si photocathode is enhanced for hydrogen evolution when a viologen derivative is chemically bonded to the electrode surface and Pt particles are dispersed within the polymer matrix [47]. The viologen mediates the transfer of the photogenerated electron to $\mathrm{H}^{+}$by the platinum to form $\mathrm{H}_{2}$. A thin platinum coating directly on the p-type silicon surface also improves the catalytic performance of the electrode. Charge conduction is generally much higher in electrically conductive polymers than in typical electroactive polymers [42-58].

Accordingly, work on charge conductive polymers in the filed of photoelectrochemistry has been directed toward stabilization of electrodes against photodegradation in electricity-generating cells. Charge conductive polymers are known to protect certain semiconductor surfaces from photodecomposition, by transmitting photogenerated holes in the semiconductor to oxidizable species in the electrolyte at a rate much higher than the thermodynamically-favoured rate of decomposition of the electrode. In a study it has been demonstrated that coating n-type silicon semiconductor photoelectrodes with a charge conductive polymer, such as polypyrrole, enhances stability against surface oxidation in electricity-generating cells. n-type GaAs has also been coated with polypyrrole to reduce photodecomposition in electricity-generating cells, although the polymer exhibited poor adhesion in aqueous electrolyte [42-58].

Despite the promising use of polypyrrole on n-type silicon to suppress photodecomposition, heretofore, whether or not conductive polymers in general could be used in conjunction with catalysts was unknown. Moreover, it can be seen that the discovery of uses for various polymer coatings on photoelectrodes has been on a case by case basis because of the empirical nature of the effects on any particular semiconductor and/or the interaction with a given electrolyte environment [42-70].

\section{Catalysts for Carbon Dioxide Reduction}

The reduction of carbon dioxide to methanol is represented as $\mathrm{CO}_{2}+6 \mathrm{H}^{+}+6 \mathrm{e}^{-} \rightleftarrows \mathrm{CH}_{3} \mathrm{OH}+\mathrm{H}_{2} \mathrm{O}$. In a study, Jr. Frese, et al. [35], carried out this reaction over the surface of a molybdenum cathode. According to them, a molybdenum cathode can reduce carbon dioxide to methanol selectively and with up to $80 \%$ to $100 \%$ faradaic efficiency. Such reductions can occur, for example, at $-0.7 \mathrm{~V}$ vs SCE at $\mathrm{pH} 4.2$, only $160 \mathrm{mV}$ negative of the standard potential corrected for $\mathrm{pH}$. However, this process is yet to be tested in a PEC cell.

In another study, Barton et al. [51], conducted a selective solar-driven reduction of $\mathrm{CO}_{2}$ to methanol using a catalyzed p-GaP based photoelectrochemical (PEC) cell in a process called chemical carbon mitigation. The photoinduced conversion of $\mathrm{CO}_{2}$ to a value-added product without the use of additional $\mathrm{CO}_{2}$ generating power source is referred to as "chemical carbon mitigation". More than $95 \%$ conversion and $100 \%$ methanol selectivity was noted in this process. However, the stability of this semiconductor is to be tested to see the feasibility of this process running on a commercial basis.

Rather in another study, Xu et al. [13], successfully reduced $\mathrm{CO}_{2}$ to methanol following a biochemical approach in which formate dehydrogenase, formaldehyde dehydrogenase, and alcohol dehydrogenase were used as catalysts. Prior to reaction, these dehydrogenase catalysts were encapsulated in an alginate-silica hybrid gel, which was formed through in situ growth of the silica precursor within the alginate solution that was followed by $\mathrm{Ca}^{2+}$ cross-linking. The methanol yields noted in this process were $98.8 \%, 71.3 \%$ and $98.1 \%$, respectively, for reactions catalyzed by free dehydrogenases, dehydrogenases immobilized in pure alginate and dehydrogenases immobilized in alginate-silica. The latter catalyst showed the methanol yield of $76.2 \%$ even after stored for 60 days. Nevertheless, these catalysts are yet to be tested in PEC cells for the same reaction.

\section{Water Oxidation Catalysts}

Recently, a path breaking observation was made at Lawrence Berkeley National Laboratory by Heinz Frei and Feng Jiao [62]. They prepared an aqueous solution containing silica particles that have been embedded with photooxidizing cobalt oxide nanocrystals plus a sensitizer to allow the water-splitting reaction to be driven by visible light. When this solution was irradiated by laser light it turned from gold to blue as the sensitizer absorbed the light. Bubbles soon begin to form as oxygen gas was released from the split water molecules. The idea of Frei and Jiao was to develop artificial leaves in which light harvesting occurs by capturing of solar photons by the oxidation of water over a bio-catalyst. Green plants perform the photooxidation of water molecules within a complex of proteins called Photosystem II, in which manganese-containing enzymes serve as the catalyst. Manganese-based organometallic complexes modeled off Photosystem II have been tested by them for the same reaction. Though these catalysts have shown some promise as photocatalysts for water oxidation but suffered from being water insoluble and none were very robust. In looking for purely inorganic catalysts that would dissolve in water and would be far more robust than biomimetic materials, Frei and Jiao turned to cobalt oxide, a highly abundant material that is an important industrial catalyst. When they have tested micron-sized particles of cobalt oxide, they found the particles were 
inefficient and not nearly fast enough to serve as photocatalysts. However, when they nano-sized the particles, it was another story. The yield for clusters of cobalt oxide $\left(\mathrm{Co}_{3} \mathrm{O}_{4}\right)$ nano-sized crystals was about 1600 times higher than for micron-sized particles and the turnover frequency (speed) was about 1140 oxygen molecules per second per cluster, which is commensurate with solar flux at ground level (approximately 1000 Watts per square meter). Frei and Jiao used mesoporous silica as their scaffold, growing their cobalt nanocrystals within the naturally parallel nanoscale channels of the silica via wet impregnation technique. The best performers were rod-shaped crystals measuring $8 \mathrm{~nm}$ in diameter and 50 $\mathrm{nm}$ in length, which were interconnected by short bridges to form bundled clusters. The bundles were shaped like a sphere with a diameter of $35 \mathrm{~nm}$. While the catalytic efficiency of the cobalt metal itself was important, they presumed that the major factor behind the enhanced efficiency and speed of the bundles was their size. However, their catalyst is yet to be tested in a reaction of water oxidation integrated with the carbon dioxide reduction step via artificial photosynthesis, which is really a challenging task.

In another study, Geletti et al. [63], developed a water soluble new inorganic metal oxide (i.e., a polyoxometalate, POM) cluster with a core consisting of four ions of the rare transition metal ruthenium, which has shown the fast and effective oxidation of water to oxygen while remaining stable itself. They say that in contrast to all other molecular catalysts for water oxidation, their catalyst does not contain any organic components and that is the reason for its stability in water. However, while Ru is more abundant and also less expensive than several other precious metals, its use would nonetheless be problematical for many large-scale green energy applications. Given this reality, they turned to the development and evaluation of POMs containing multiple earth-abundant metals as potential water oxidation catalysts (WOCs). Finally, they succeeded in realising a fast soluble carbon-free molecular water oxidation catalyst based on abundant metals (Co, $\mathrm{W}$ and $\mathrm{P})[64,65]$. The $\mathrm{POM},\left[\mathrm{Co}_{4}\left(\mathrm{H}_{2} \mathrm{O}\right)_{2}\left(\mathrm{PW}_{9} \mathrm{O}_{34}\right)_{2}\right]^{10-}$ prepared by them was found to be comprising a $\mathrm{Co}_{4} \mathrm{O}_{4}$ core stabilized by oxidatively resistant polytungstate ligands. It was also found to be hydrolytically and oxidatively stable homogenous WOC that self assembles in water from salts of Co, W and P. With [Ru(bpy)3] $]^{3+}$ (bpy is 2,2'-bi-pyridine) as the oxidant, this catalyst showed catalytic turnover frequencies for $\mathrm{O}_{2}$ production $\geq 5 \mathrm{~s}^{-1}$ at $\mathrm{pH}=8$. According to them, their next challenge is to integrate these inorganic complexes into photoactive systems, which efficiently convert solar energy into chemical energy. So far, energy is still obtained from chemical oxi- dants in their studies [65].

\section{Scope for the Future Research}

The above information clearly suggests that among various routes proposed for conversion of $\mathrm{CO}_{2}$ to methanol or to any other value added chemical, the photoelectrochemical (PEC) cells have an edge over other process. In order to realize efficient PEC cells for this reaction, 1) an n-type semiconductor with desired bade gap and band edges for photoanode (e.g., pure $\mathrm{TiO}_{2}, \mathrm{ZnO}, \mathrm{CdS}$, etc.); 2) a p-type semi-conductor with desired band gap and band edges for photocathode (e.g., doped $\mathrm{TiO}_{2}, \mathrm{ZnO}, \mathrm{GaP}$, etc.); 3) a catalyst for performing water oxidation reaction over or near to the surface of photoanode (e.g., polyoxometallates [63-65]), and 4) a catalyst to perform $\mathrm{CO}_{2}$ reduction reaction over or near to the surface of photocathode (e.g., pyridinium ions over the surface of p-GaP $[18,41,51])$ are essential. Furthermore, these four systems should exhibit quite stability in water under solar irradiation. In addition to these, it is also required to understand the following underlined mechanisms for successful realization of PEC cells for converting $\mathrm{CO}_{2}$ to value added chemicals.

1) Underlined mechanisms in water oxidation and $\mathrm{CO}_{2}$ reduction reactions over the surfaces of photoanode and photocathode, respectively;

2) The mechanisms involved in the dissolution and evolution of $\mathrm{CO}_{2}$ in water soluble organic solvents such as monomethanol amine, etc., to perform $\mathrm{CO}_{2}$ reduction reactions in PEC cells containing water based electrolyte;

3) Interaction of conducting polymers with both photoanode and photo-cathode materials;

4) Underlined mechanisms in the corrosion of nonoxide (for e.g., $\mathrm{GaP}$ and $\mathrm{CdS}$ ) semi-conducting materials in water upon solar irradiance and in the passivation of these semi-conducting materials surfaces against photodegradation;

5) Underlined mechanisms in the suppression of $\mathrm{H}_{2}$ formation from $\mathrm{H}^{+}$ions produced over the surface of photo-anode upon solar irradiation in PEC cells contained water based electrolyte at the surface of photocathode;

6) The behaviour of electron and ion transporting of water-soluble organics/catalysts in PEC cells;

7) Finally, integration of various systems required for conversion of carbon dioxide to methanol or to any value added chemical in PEC cells.

\section{Acknowledgements}

Author wishes to thank Dr. G. Sundararajan, Director, ARCI, Hyderabad for his kind encouragement and for giving permission to publish this review article. 


\section{REFERENCES}

[1] A. B. Robinson, N. E. Robinson and A. Soon, "Environmental Effects of Increased Atmospheric Carbon Dioxide," Journal of American Physicians and Surgeons, Vol. 12, 2007, pp. 79-90.

[2] IPCC, "Summary for Policemakers," Climate Change 2007: The Physical Science Basis, Contribution of Working Group I to the Fourth Assessment Report of the Intergovermental Panel on Climate Change, 4 May 2007. http://ipcc-wgl.ucar.edu/wgl/Report/AR4WG1Print SPM. pdf/

[3] J. David and H. Herzog, "The Cost of Carbon Capture," Proceedings of the 5th International Conference on Greenhouse Gas Control Technologies, Cairns, 13-16 August 2000, pp. 985-990.

[4] M. Gupta, I. Coyle and K. Thambimuthu, " $\mathrm{CO}_{2}$ Capture Technologies and Opportunities in Canada," Strawman Document for $\mathrm{CO}_{2}$ Capture and Storage (CC \& S) Technology Roadmap, 1st Canadian CC \& S Technology Roadmap Workshop, Calgary, September 2003, pp. 18-19.

[5] R. Priddle, "World Energy Outlook 2002," 2nd Edition, International Energy Agency, IEA/OECD, Paris, 2002. http://www.iea.org/textbase/nppdf/free/2000/weo2002.pdf

[6] UDI, "World Electric Power-Plants Database," Utility Data Institute, McGraw-Hill, Washington DC, 2003.

[7] ENI, "World Oil and Gas Review 2004," Rome, 2004. http://www.agip.it/

[8] World Energy Council, " $19^{\text {th }}$ Survey of World Energy Resources," World Energy Council, London, 2001. http://www.worldenergy.org/wec-geis/publications/defaul $\mathrm{t} /$ launches/ser/ser.asp

[9] G. Moritis, "EOR Continues to Unlock Oil Resources," Oil \& Gas Journal, Vol. 12, 2004, pp. 53-65.

[10] M. Halmon, "Photoelectrochemical Reduction of Aqueous Carbon-Dioxide on p-Type Gallium-Phosphide in Liquid Junction Solar-Cells," Nature, Vol. 275, 1978, pp. 115-116. doi:10.1038/275115a0

[11] A. Aruchamy, G. Aravamudan and G. V. Subba Rao, "Semiconductor Based Photoelectrochemical Cells for Solar Energy Conversion-An Overview," Bulletin of Material Science, Vol. 4, No. 5, 1982, pp. 483-526. doi:10.1007/BF02824960

[12] L. R. Sheppard and J. Nowotny, "Materials for Photoelectrochemical Energy Conversion," Advances in Applied Ceramics, Vol. 106, No. 1-2, 2007, pp. 9-20. doi:10.1179/174367607X152353

[13] S. W. Xu, Y. Lu, J. Li, Z. Y. Jiang and H. Wu, "Efficient Conversion of $\mathrm{CO}_{2}$ to Methanol Catalyzed by Three Dehydrogenases Co-Encapsulated in an Alginate-Silica (ALG$\mathrm{SiO}_{2}$ ) Hybrid Gel," Industrial \& Engineering Chemistry Research, Vol. 45, No. 13, 2006, pp. 4567-4573. doi:10.1021/ie0514071

[14] G. A. Olah, A. Geoppert and G. K. S. Prakash, "Chemical Recycling of Carbon Dioxide to Methanol and Dimethylether: From Greenhouse Gas to Renewable, Environmentally Carbon Neutral Fuels and Synthetic Hydro- carbons," The Journal of Organic Chemistry, Vol. 74, No. 2, 2009, pp. 487-498. doi:10.1021/jo801260f

[15] M. Khoshtinat, N. A. S. Amin and I. Noshadi, "A Review of Methanol Production from Methane Oxidation via Non-Thermal Plasma Reactor," World Academy of Science, Engineering and Technology, Vol. 62, 2010, pp. 354-358.

[16] E. Thimsen, F. L. Formal, M. Gratzel and S. C. Warren, "Influence of Plasmonic Au Nanoparticles on the Photoactivity of $\mathrm{Fe}_{2} \mathrm{O}_{3}$ Electrodes for Water Splitting," Nano Letters, Vol. 11, No. 1, 2011, pp. 35-43. doi: $10.1021 / \mathrm{nl} 1022354$

[17] D. J. Darensbourg, "Chemistry of Carbon Dioxide Relevant to Its Utilization: A Personal Perspective," Inorganic Chemistry, Vol. 49, No. 23, 2010, pp. 10765-10780. doi:10.1021/ic101800d

[18] E. B. Cole, P. S. Lakkaraju, D. M. Rampulla, A. J. Morris, E. Abelev and A. B. Bocarsly, "Using a One-Electron Shuttle for the Multielectron Reduction of $\mathrm{CO}_{2}$ to Methanol: Kinetic, Mechanistic, and Structural Insights," Journal of the American Chemical Society, Vol. 132, No. 33, 2010, pp. 11539-11551. doi:10.1021/ja1023496

[19] P. M. Zimmerman, Z. Zhang and C. B. Musgrave, "Simultaneous Two-Hydrogen Transfer as a Mechanism for Efficient $\mathrm{CO}_{2}$ Reduction," Inorganic Chemistry, Vol. 49, No. 19, 2010, pp. 8724-8728. doi:10.1021/ic100454z

[20] M. Pehnt, "Fuel Cells in the Power Market: Separating the Hope from the Hype," Presentation at CAN Europe meeting, Brussels, 27 May 2004.

http://www.climnet.org/CTAP/workshop2004/Presentatio nsWS2.htm/

[21] A. J. Traynor and R. J. Jensen, "Direct Solar Reduction of $\mathrm{CO}_{2}$ to Fuel: First Prototype Results," Industrial \& Engineering Chemistry Research, Vol. 41, No. 8, 2002, pp. 1935-1939. doi:10.1021/ie010871x

[22] C. Mandil, "Prospects for $\mathrm{CO}_{2}$ Capture and Storage," International Energy Agency and Energy Technology Analysis, IEA Publications, 2004. http://www.iea.org/textbase/nppdf/free/2004/prospects.pdf

[23] S. Bachu, "Sequestration of $\mathrm{CO}_{2}$ in Geological Media: Criteria and Approach for Site Selection in Response to Climate Change," Energy Conversion and Management, Vol. 41, No. 9, 2000, pp. 953-970. doi:10.1016/S0196-8904(99)00149-1

[24] S. Bachu and J. J. Adams, "Sequestration of $\mathrm{CO}_{2}$ in Geological Media in Response to Climate Change: Capacity of Deep Saline Aquifers to Sequester $\mathrm{CO}_{2}$ in Solution," Energy Conversion and Management, Vol. 44, No. 20, 2003, pp. 3151-3175. doi:10.1016/S0196-8904(03)00101-8

[25] R. G. Bruant, M. A. Celia, A. J. Guswa and C. A. Peters, "Safe Storage of $\mathrm{CO}_{2}$ in Deep Saline Aquifers," Environmental Science and Technology, Vol. 36, No. 11, 2002, pp. 240A-245A. doi:10.1021/es0223325

[26] J. Gale, "Using Coal Seams for $\mathrm{CO}_{2}$ Sequestration," Geologica Belgica, Vol. 7, No. 3-4, 2004, pp. 99-103.

[27] T. Holt, J. I. Jensen and E. Lindeberg, "Underground 
Storage of $\mathrm{CO}_{2}$ in Aquifers and Oil Reservoirs," Energy Conversion and Management, Vol. 36, No. 6-9, 1995, pp. 535-538. doi:10.1016/0196-8904(95)00061-H

[28] C. W. Hustad, "Infrastructure for $\mathrm{CO}_{2}$ Collection, Transport and Sequestration," The 3rd Nordic Mini-Symposium on Carbon Dioxide Storage, Presented Paper, Trondheim, 1-2 October 2003.

[29] F. V. Bergen, J. Gale, K. J. Damen and A. F. B. Wildenborg, "Worldwide Selection of Early Opportunities for $\mathrm{CO}_{2}$-Enhanced Oil Recovery and $\mathrm{CO}_{2}$-Enhanced Coal Bed Methane Production," Energy, Vol. 29, No. 9-10, 2004, pp. 1611-1621. doi:10.1016/j.energy.2004.03.063

[30] C. Salvador, D. Lu, E. J. Anthony and J. C. Abanades, "Enhancement of $\mathrm{CaO}$ for $\mathrm{CO}_{2}$ Capture in an $\mathrm{FBC}$ Environment," Chemical Engineering Journal, Vol. 96, No. 3, 2003, pp. 187-195. doi:10.1016/j.cej.2003.08.011

[31] J. C. Hicks, J. H. Drese, D. J. Fauth, McMahan L. Gray, G. Qi and C. W. Jones, "Designing Adsorbents for $\mathrm{CO}_{2}$ Capture from Flue Gas-Hyperbranched Aminosilicas Capable of Capturing $\mathrm{CO}_{2}$ Reversibly," Journal of the American Chemical Society, Vol. 130, No. 10, 2008, pp. 2902-2903. doi:10.1021/ja077795v

[32] S. K. Ritter, "What Can We Do with Carbon Dioxide? Scientists Are Trying to Find Ways to Convert the Plentiful Greenhouse Gas into Fuels and Other Value-Added Products," Chemical \& Engineering News, Vol. 85, No. 18, 2007, pp. 11-17.

[33] M.-J. Choi and D.-H. Cho1, "Review: Research Activities on the Utilization of Carbon Dioxide in Korea," Clean, Vol. 36, No. 5-6, 2008, pp. 426-432.

[34] J. W. Dijkstra and D. Jansen, "Novel Concepts for $\mathrm{CO}_{2}$ Capture with SOFC," Proceedings of the 6th International Conference on Greenhouse Gas Control Technologies, Kyoto, 1-4 October 2002, pp. 161-166. doi:10.1016/B978-008044276-1/50026-X

[35] K. W. Frese Jr., S. C. Leach and D. P. Summers, "Electrochemical Reduction of Aqueous Carbon Dioxide to Methanol," US Patent No. 4,609,441, 2 September 1986.

[36] S. T. Hussain, M. M. Muhammad and H. U. Rehman, "Novel Process and Catalyst for Carbon Dioxide Conversion to Energy Generating Products," Patent file numbers: IPC8 Class: AC07C2706FI, USPC Class: 518712.

[37] B. Dickson, I. Yashayaev, J. Meincke, B. Turrell, S. Dye and J. Holfort, "Rapid Freshening of the Deep North Atlantic Ocean over the Past Four Decades," Nature, Vol. 416, No. 6883, 2002, pp. 832-837. doi:10.1038/416832a

[38] M. R. Dubois and D. L. Dubois, "Development of Molecular Electrocatalysts for $\mathrm{CO}_{2}$ Reduction and $\mathrm{H}_{2}$ Production/Oxidation," Accounts of Chemical Research, Vol. 42, No. 12, 2009, pp. 1974-19982. doi:10.1021/ar900110c

[39] R. J. Jensen, J. L. Lyman, J. D. King and R. D. Guettler, "Solar Reduction of $\mathrm{CO}_{2}$ ", US Patent No. 6,066,187, 23 May 2000.

[40] Exxon Mobil Algae Biofuels Research and Development Program, 1978. http://www.exxonmobil.com/corporate/files/news_pub_al gae_factsheet.pdf/

[41] G. Seshadri, C. Lin and A. B. Bocarsly, "A New Electrocatalyst for the Reduction of Carbon Dioxide to Methanol at Low Overpotential," Journal of Electroanalytical Chemistry, Vol. 372, No. 1-2, 1994, pp. 145-150. doi:10.1016/0022-0728(94)03300-5

[42] N. Spataru, K. Tokuhiro, C. Terashima, T. N. Rao and A. Fujishima, "Electrochemical Reduction of Carbon Dioxide at Ruthenium Dioxide Deposited on Boron-Doped Diamond," Journal of Applied Electrochemistry, Vol. 33, No. 12, 2003, pp. 1205-1210. doi:10.1023/B:JACH.0000003866.85015.b6

[43] A. Fujishima, D. A. Tryk and T. N. Rao, "New Approaches in $\mathrm{CO}_{2}$ Reduction," Advances in Chemical Conversions for Mitigating Carbon Dioxide, Vol. 114, 1998, pp. 31-42. In: T. Inuiv, M. Anpo, K. Izui, S. Yanagida and T. Yamaguchi, Ed., Studies in Surface Science and Catalysis, Book Series, Elsevier, Amsterdam.

[44] J. Ryu, T. N. Andersen and H. Eyring, "Electrode Reduction Kinetics of Carbon Dioxide in Aqueous Medium," The Journal of Physical Chemistry, Vol. 76, No. 22, 1972, pp. 3278-3286. doi:10.1021/j100666a029

[45] K. Ogura and M. D. S. Viallalpando, " $\mathrm{CO}_{2}$ Electrochemical Reduction via Adsorbed Halide Anions," Journal of Operations Management, Vol. 63, No. 1, pp. 35-38. http://www.springerlink.com/content/818vx0624h6112lk/ fulltext.pdf

[46] S. Kapusta and N. Hackerman, "The Electroreduction of Carbon Dioxide and Formic Acid on Tin and Indium Electrodes," Journal of The Electrochemical Society, Vol. 130, No. 3, 1983, pp. 607-613. doi:10.1149/1.2119761

[47] K. Ohashi, J. McCann and J. O. M. Bockris, "Stable Photoelectrochemical Cells for Splitting of Water," Nature, Vol. 266, No. 5603, 1977, pp. 610-611. doi: $10.1038 / 266610 \mathrm{a} 0$

[48] R. Bhardwaj, R. L. Pan and E. L. Gross, "Solar-Energy Conversion by Chloroplast Photoelectrochemical Cells," Nature, Vol. 289, No. 5796, 1981, pp. 396-398. doi:10.1038/289396a0

[49] S. Licht, "A Description of Energy-Conversion in Photoelectrochemical Solar-Cells," Nature, Vol. 330, No. 6144, 1987, pp. 148-151. doi:10.1038/330148a0

[50] M. Gratzel, "Photoelectrochemical Cells," Nature, Vol. 414, No. 6861, 2001, pp. 338-344. doi:10.1038/35104607

[51] E. E. Barton, D. M. Rampulla and A. B. Bocarsly, "Selective Solar-Driven Reduction of $\mathrm{CO}_{2}$ to Methanol Using a Catalyzed p-GaP Based Photoelectrochemical Cell," Journal of the American Chemical Society, Vol. 130, No. 20, 2008, pp. 6342-6344. doi:10.1021/ja0776327

[52] R. M. Williams and A. Rembaum, "Photoelectrochemical Electrodes," US Patent No. 4,414,080, 8 November 1983.

[53] A. J. Frank, "Organic Conductive Films for Semiconductor Electrodes," US Patent No. 4,461,691, 24 July 1984.

[54] M. Gratzel and K. Kalyanasundaram, "Artificial Photosynthesis: Efficient Dye-Sensitized Photoelectrochemical Cells for Direct Conversion of Visible-Light to Electric- 
ity," Current Science, Vol. 66, No. 10, 1994, pp. 706-714.

[55] A. J. Bard, "Semiconductor Photoelectrochemical Cells," Journal of the Electrochemical Society, Vol. 126, No. 3, 1979, pp. C145-C145.

[56] D. Haneman, "Surfaces for Photoelectrochemical Cells," Surface Science, Vol. 86, 1979, pp. 462-485. doi:10.1016/0039-6028(79)90424-2

[57] J. Manassen, G. Hodes and D. Cahen, "Photoelectrochemical Cells," Chemical Technology, Vol. 11, No. 2, 1981, pp. 112-117.

[58] S. Yae, T. Kobayashi, M. Abe, N. Nasu, N. Fukumuro, S. Ogawa, N. Yoshida, S. Nonomura, Y. Nakato and H. Matsuda, "Solar to Chemical Conversion Using Metal Nanoparticle Modified Microcrystalline Silicon Thin Film Photoelectrode," Solar Energy Materials \& Solar Cells, Vol. 91, No. 4, 2007, pp. 224-229.

[59] A. Fujishima and K. Honda, "Electrochemical Photolysis of Water at a Semiconductor Electrode," Nature, Vol. 238, No. 5358, 1972, pp. 37-38. doi:10.1038/238037a0

[60] A. Fujishima, K. Kohayakawa and K. Honda, "Formation of Hydrogen Gas with an Electrochemical Photo-Cell," Bulletin of the Chemical Society of Japan, Vol. 48, No. 3, 1975, pp. 1041-1042. doi:10.1246/bcsj.48.1041

[61] T. Watanabe, T. Fujishima and K. Honda, "Photoelctrochemical Hydrogen Production," In: T. Ohta, Ed., Solar Hydrogen Energy Systems, Pergamon Press, Oxford, 1979, pp. 137-169.

[62] F. Jiao and H. Frei, "Water Oxidation: Nanostructured Cobalt Oxide Clusters in Mesoporous Silica as Efficient Oxygen-Evolving Catalysts," Angewandte Chemie, Vol. 121, No. 10, 2009, pp. 1873-1876. doi:10.1002/ange.200805534

[63] Y. V. Geletii, B. Botar, P. Kogerler, D. A. Hillesheim, D. G. Musaev and C. L. Hill, "Oxygen Generation: An All-Inorganic, Stable, and Highly Active Tetraruthenium Homogeneous Catalyst for Water Oxidation," Angewandte Chemie, Vol. 47, No. 21, 2008, pp. 3896-3899. doi:10.1002/anie. 200705652

[64] Q. Yin, J. M. Tan, C. Besson, Y. V. Geletii, D. G. Musaev, A. E. Kuznetsov, Z. Luo, K. I. Hardcastle and C. L. Hill, "A Fast Soluble Carbon-Free Molecular Water Oxidation Catalyst Based on Abundant Metals," Science, Vol. 328, No. 5976, 2010, pp. 342-345. doi:10.1126/science. 1185372

[65] Y. V. Geletii, Q. Yin, Y. Hou, Z. Huang, H. Ma, J. Song, C. Besson, Z. Luo, R. Cao, K. P. O'Halloran, C. Zhao, J. W. Vickers, Y. Ding, S. Mohebbi, A. E. Kuznetsov, D. G. Musaev, T. Lian and C. L. Hill, "Polyoxometalates in the Design of Effective and Tunable Water Oxidation Catalysts-A Review," Israel Journal of Chemistry, Vol. 51, No. 2, 2011, pp. 238-246. doi:10.1002/ijch.201100021

[66] K. V. C. Rao, M. R. Rao, M. P. Nair, V. G. Kumar and C. G. R. Nair, " $\mathrm{TiO}_{2}-\mathrm{SiO}_{2}$ Based Photoanodes in Photoelectrochemical Cells-Performance and Evaluation Studies," International Journal of Hydrogen Energy, Vol. 14, No. 5, 1989, pp. 295-301. doi:10.1016/0360-3199(89)90129-8

[67] B. van der Zwaan and A. Rabl, "The Learning Potential of Photovoltaics: Implications for Energy Policy," Energy Policy, Vol. 32, No. 13, 2004, pp. 1545-1554. doi:10.1016/S0301-4215(03)00126-5

[68] S. Chandra, P. K. Pandey and R. C. Agrawal, "Solar Energy Conversion by Photoelectrichemical Cells Using Chemical-Bath-Deposited CdS Films," Journal of Physics D: Applied Physics, Vol. 13, No. 9, 1980, pp. 1757-1760. doi:10.1088/0022-3727/13/9/025

[69] A. Gupta and A. S. N. Murthy, "Photoelectrochemical Behaviour of Polypyrrole Coated Cadmium Telluride," Solar Energy Materials and Solar Cells, Vol. 28, No. 2, 1992, pp. 113-121. doi:10.1016/0927-0248(92)90003-8

[70] T. Bak, J. Nowotny, M. Rekas and C. C. Sorrell, "Review Article: Photo-Electrochemical Hydrogen Generation from Water Using Solar Energy. Materials-Related Aspects," International Journal of Hydrogen Energy, Vol. 27, No. 10, 2002, pp. 991-1022. 